\title{
Retrieval of desert dust aerosol vertical profiles from IASI measurements in the TIR atmospheric window
}

\author{
S. Vandenbussche, S. Kochenova, A. C. Vandaele, N. Kumps, and M. De Mazière \\ Belgian Institute for Space Aeronomy, Brussels, Belgium \\ Correspondence to: S. Vandenbussche (sophie.vandenbussche@aeronomie.be) \\ Received: 19 April 2013 - Published in Atmos. Meas. Tech. Discuss.: 22 May 2013 \\ Revised: 20 August 2013 - Accepted: 2 September 2013 - Published: 7 October 2013
}

\begin{abstract}
Desert dust aerosols are the most prominent tropospheric aerosols, playing an important role in the earth's climate. However, their radiative forcing is currently not known with sufficient precision to even determine its sign. The sources of uncertainty are multiple, one of them being a poor characterisation of the dust aerosol's vertical profile on a global scale. In this work, we tackle this scientific issue by designing a method for retrieving dust aerosol vertical profiles from Thermal Infrared measurements by Infrared Atmospheric Sounding Interferometer (IASI) instruments onboard the Metop satellite series. IASI offers almost global coverage twice a day, and long (past and future) time series of radiances, therefore being extremely well suited for climate studies. Our retrieval follows Rodger's formalism and is based on a two-step approach, treating separately the issues of low altitude sensitivity and difficult a priori definition. We compare our results for a selected test case above the Atlantic Ocean and North Africa in June 2009, with optical depth data from MODIS, aerosol absorbing index from GOME-2 and OMI, and vertical profiles of extinction coefficients from CALIOP. We also use literature information on desert dust sources to interpret our results above land. Our retrievals provide perfectly reasonable results in terms of optical depth. The retrieved vertical profiles (with on average 1.5 degrees of freedom) show most of the time sensitivity down to the lowest layer, and agree well with CALIOP extinction profiles for medium to high dust optical depth. We conclude that this new method is extremely promising for improving the scientific knowledge about the 3-D distribution of desert dust aerosols in the atmosphere.
\end{abstract}

\section{Introduction}

Windblown dust from arid regions is the most prominent type of aerosols in the troposphere, in global annual average mass burden (Textor et al., 2006), present mainly, but not exclusively, in the tropics. Dust particles absorb and scatter the incoming and reflected solar light: this is the short-wave (SW) direct effect. In addition to that, these aerosols have a longwave (LW) direct effect: they absorb and scatter the thermal emission from the surface and the atmosphere, and they emit thermal radiation themselves. These effects are often assessed in terms of radiative forcing (RF), which is the net (incoming minus outgoing) change in energy at a defined altitude (e.g. the top-of-atmosphere, tropopause or surface), due to a change in a climatic parameter (e.g. the aerosol size, optical properties, total atmospheric load, etc.). Following the Fourth Assessment Report of the Intergovernmental Panel on Climate Change (Forster et al., 2007), the anthropogenic direct dust RF at the top-of-atmosphere would be slightly negative, with a $90 \%$ confidence interval including both positive and negative values. The uncertainty in the sign of this total forcing arises from the fact that the SW and LW global effects are competing, being respectively negative and positive, and are not yet quantified accurately enough to allow the determination of the dominant effect. This is of course also true for the direct RF due to naturally occurring atmospheric dust. It has been shown (Perrone et al., 2012; Zhang and Christopher, 2003; Claquin et al., 1998; Liao and Seinfeld, 1998) that dust direct RF mainly depends on total optical depth (SW and LW), aerosol refractive index (mostly but not only SW), aerosol mean particle size (SW and LW), aerosol vertical distribution (LW, SW only for cloudy scenes), water vapour and temperature vertical profiles (only LW), and 
surface albedo (only SW). Amongst all these parameters, the dust vertical distribution is currently poorly characterised on a global scale. Indeed, a very recent paper by Winker et al. (2013) reports for the first time a global 3-D monthly climatology of tropospheric aerosols, but there is no data set with higher temporal coverage.

In addition to its direct radiative effect, air-borne dust exerts an indirect effect on the climate, through its interaction with clouds. Dust particles act as cloud condensation or ice nuclei, modifying the droplets/ice particles size distribution and therefore altering the optical properties of clouds, their horizontal and vertical extent, their lifetime and the amount of rain (e.g., Bangert et al., 2012; Lee, 2011; Li et al., 2011; Koehler et al., 2010). This indirect effect mainly depends on the aerosol particles number density (Bangert et al., 2012) and the relative vertical location of cloud and aerosol layers (Quijano et al., 2000), again pointing to the necessity of a better characterisation of the 3-D distribution of dust aerosols in the atmosphere.

In recent years, a growing effort has been devoted to improve the knowledge of dust characteristics: physical and optical properties, atmospheric load, sources, transport, etc. A number of recent field campaigns, the two SAharan Mineral dUst experiMents (SAMUM) in 2006 and 2008 (Ansmann et al., 2011) and the Geostationary Earth Radiation Budget Intercomparisons of Long-wave and Short-wave radiation (GERBILS) in 2007 (Christopher et al., 2009), have provided valuable information on dust particle size distribution (PSD), shape and refractive index. These microphysical and optical properties are then used for obtaining dust load in the atmosphere on a global scale by retrievals from satellite remote sensing measurements (e.g., Carboni et al., 2012). The currently most advanced aerosol retrievals from satellite sensors are based on UV, visible or near-infrared wavelengths, for example, GOME (ERS-2), GOME2 (Metop), OMI (Aura), MODIS (Aqua and Terra), MISR (Terra), MERIS (Envisat), Polder (PARASOL), or CALIOP (CALIPSO). Short-wave aerosol properties are therefore characterised on an operational basis using data from many different instruments and measurement techniques. Retrievals of aerosol long-wave optical properties are less well developed but have received great attention these last years. These properties cannot be inferred from short-wave measurements, because short-wave and longwave spectral windows are not sensitive to the same particle sizes. Current thermal infrared (TIR) dust retrievals using measurements from AIRS (Aqua), IASI (Metop) or SEVIRI (MSG) provide total optical depth (OD, Pierangelo et al., 2004, 2005; Zhang et al., 2006; De Paepe and Dewitte, 2009; Peyridieu et al., 2010, 2012; DeSouza-Machado et al., 2010; Klüser et al., 2011) and in some cases particle size (Pierangelo et al., 2005; Zhang et al., 2006; Peyridieu et al., 2012), mineral composition (Klüser et al., 2012) or an equivalent or radiative altitude, being that of the atmospheric model's layer that was filled with aerosols for the re- trieval (Pierangelo et al., 2004; Peyridieu et al., 2010, 2012; DeSouza-Machado et al., 2010). This altitude is obtained either from look-up tables, or after running the retrieval successively with aerosols located at different levels and selecting the one that leads to the lowest residuals. This limited description of dust's altitude is most probably suited for the assessment of its LW direct radiative effect. However, the dust altitude effect on SW forcing in the presence of clouds, and the dust-clouds interactions depend on the real vertical distribution of dust, which is in most cases not limited to a wellmixed single layer of fixed geometric width.

An additional application that would benefit from a better characterisation of the vertical profile of aerosols in the atmosphere is the improvement and validation of dust emission and transport models, which should be able to produce realistic aerosol vertical profiles for a correct evaluation of dust radiative effect (see for example Zhang et al., 2013). In particular, a better characterisation of dust OD and vertical distribution near the sources (therefore above land) is needed.

Sokolik et al. (1998) and Sokolik (2002) have shown that dust presents a clear typical V-shaped signature in the TIR atmospheric window $\left(800-1200 \mathrm{~cm}^{-1}\right.$ or $\left.8.3-12.5 \mu \mathrm{m}\right)$. In this paper, we propose a strategy for the retrieval of airborne desert dust concentration vertical profiles, using TIR radiance data collected by the hyperspectral high-resolution IASI instrument onboard Metop-A. In Sect. 2, we describe the IASI instrument and the other satellite data sets used in this work for comparisons. Section 3 deals with challenges that go along with establishing a desert dust aerosol retrieval, including aerosol parameterization, ancillary surface and atmospheric data, and particular challenges related to the retrieval of aerosol vertical profiles instead of aerosol single layers. We then describe (Sect. 4) the radiative transfer and retrieval tools used in this work and the proposed desert dust vertical profiles retrieval strategy. This is followed by a testcase study (Sect. 5): a large dust plume above both the Saharan desert and the Atlantic Ocean on 22 June 2009. Results obtained from IASI measurements using our retrieval strategy are discussed regarding their quality and sensitivity to different parameters, and compared with relevant data from other satellite instruments. The paper ends with conclusions and further work perspectives.

\section{Satellite instruments and data}

In this study we have performed retrievals of aerosol characteristics from IASI spectra and compared our results to data obtained by various instruments on different platforms. In this section we briefly describe the considered instruments and selected data sets. 


\subsection{IASI}

The Infrared Atmospheric Sounding Interferometer (IASI) has been developed by the Centre National d'Etudes Spatiales (CNES) in cooperation with the European Organisation for the Exploitation of Meteorological Satellites (EUMETSAT). IASI has been flying onboard the Metop-A platform since October 2006, on a mid-morning sun-synchronous polar orbit (09:30 local solar equator crossing time, descending node). IASI is a Fourier Transform Michelson interferometer measuring radiation at nadir in the infrared from 645 to $2760 \mathrm{~cm}^{-1}$ with a resolution of $0.5 \mathrm{~cm}^{-1}$ after apodization, and a radiometric noise evaluated smaller than $9 \times$ $10^{-7} \mathrm{~W} \mathrm{~cm}^{-2}\left(\mathrm{Srcm}^{-1}\right)^{-1}$ or $0.2 \mathrm{~K}$ in the TIR atmospheric window (Clerbaux et al., 2009). It has a swath width of $2200 \mathrm{~km}\left(48.3^{\circ}\right.$ viewing angle range on both sides off nadir), and scans across-track in 30 elementary fields of view, each composed of 4 instantaneous fields of view of $12 \mathrm{~km}$ diameter at sub-satellite point. IASI offers almost global coverage twice per day thanks to the platform's orbital parameters, wide swath width and the availability of thermal emission radiance in presence and absence of sunlight.

A second IASI instrument was launched on 17 September 2012, onboard the Metop-B platform, and a third one is planned to be launched five years later, leading to a total long-term record of TIR radiances with nominally identical characteristics, spanning at least $15 \mathrm{yr}$. A slightly modified version of IASI, with reduced radiometric noise and enhanced spectral resolution, is planned as part of the 3 EPSSG Sat-A platforms planned to provide data from 2020 to 2040. Time series of TIR radiances from IASI-like instruments will therefore cover at least the 2006-2040 time frame.

In this work we have exploited IASI operational level 1c and level 2 data distributed by the EUMETCast system.

\subsection{MODIS}

Moderate Resolution Imaging Spectroradiometer (MODIS) instruments have been flying onboard the Terra and Aqua platforms from the National Aeronautics and Space Administration (NASA) since December 1999 and May 2002, on polar mid-morning (09:30 local solar time, very close to Metop-A) and mid-afternoon orbits (A-train constellation, crossing the equator at 13:30 local solar time, ascending node), respectively. MODIS has 36 channels spanning the $0.41-15 \mu \mathrm{m}$ spectral range. Channels for the current aerosol retrieval are in the range 0.47-2.13 $\mu \mathrm{m}$ (Remer et al., 2002).

For comparisons with results of the aerosol retrievals presented here, we used the aerosol optical thickness from the Aerosol Cloud Daily level 3 global v5.1 (MOD08 or MYD08 files), provided on a $1^{\circ}$ latitude/longitude grid. We used both the standard $(0.55 \mu \mathrm{m})$ and Deep Blue $(0.66 \mu \mathrm{m})$ OD fields. The Deep Blue product provides aerosol OD over bright surfaces such as the desert, where the standard product usually fails. The Deep Blue product is, at least for the test-case we have selected, provided only for MODIS/Aqua.

\subsection{GOME-2 and OMI Aerosol Absorbing Index}

The second Global Ozone Monitoring Experiment (GOME2) flies onboard Metop-A, as IASI. GOME-2 consists of nadir-scanning grating spectrometers measuring the sunlight in the range 250 to $790 \mathrm{~nm}$, backscattered or reflected by earth and its atmosphere.

The Ozone Monitoring Instrument (OMI) flies onboard the NASA Aura platform launched in July 2004 as part of the A-train. OMI is a nadir-viewing instrument measuring the earth's backscattered radiation from 270 to $500 \mathrm{~nm}$.

The Aerosol Absorbing Index (AAI) is an operational product from the EUMETSAT Satellite Application Facility on Ozone and Atmospheric Chemistry Monitoring (O3M SAF) and the Koninklijk Nederlands Meteorologisch Instituut (KNMI). The AAIs are available from the Tropospheric Emission Monitoring Internet Service website (www.temis. $\mathrm{nl}$ ). The AAI indicates the presence of absorbing aerosols in the troposphere (de Graaf et al., 2005), by separating absorbing and scattering effects in the UV. Its absolute value depends on a number of parameters as the aerosol OD, the height of the layer and the microphysical properties of the aerosols.

\subsection{CALIOP}

The Cloud-Aerosol Lidar with Orthogonal Polarization (CALIOP) instrument is part of the Cloud-Aerosol Lidar and Infrared Pathfinder Satellite Observations (CALIPSO) mission (Winker et al., 2009). This platform was launched as part of the A-train constellation. CALIOP has two co-aligned lasers (532 and $1064 \mathrm{~nm}$ ) with beam diameters of $70 \mathrm{~m}$ at the earth's surface. The instrument makes measurements during day and night, every $335 \mathrm{~m}$ along the ground track of the platform, with a vertical sampling resolution of $30 \mathrm{~m}$. CALIOP measurements were designed to provide vertical profiles of aerosol attenuated backscatter and depolarisation, from which aerosol backscatter and extinction can be derived using an inversion algorithm.

For comparisons with the aerosol retrievals presented in this work, we used the Cloud and Aerosol Profile level 2 v3.01 extinction coefficient profiles at $1064 \mathrm{~nm}$, still considered provisional. An evaluation of this product can be found in Redemann et al. (2012). We have filtered the extinction data using the Extinction Quality Control flag (maximum value of 7 was accepted, meaning that the retrieval was successful; more information on quality flags may be found in the CALIPSO Quality Statements on the NASA Langley Research Center website). Negative extinction values were removed from the data set. We have also used the Atmospheric Volume Descriptor feature classification flag which allows classifying aerosols in different categories as clean marine, 
dust, polluted continental, clean continental, polluted dust, smoke, other or unknown. When comparing IASI retrievals and CALIOP data, one should remain aware that there is always a time difference of about $4 \mathrm{~h}$ between measurements by these two instruments.

\section{Challenges of aerosol retrievals in the Thermal Infrared region}

As detailed in the introduction, the LW radiative effect of dust aerosols depends on many parameters, and cannot be reduced to an OD. Indeed, OD contains only the information on the extinction part of the aerosol effect, depending on the PSD and the refractive index. The characterisation of the emission part is necessary to assess the total LW impact. Aerosols thermal emission is, in the local thermal equilibrium approximation, that of a grey body with an emissivity of (1-ssa) where ssa is the single scattering albedo. Therefore the aerosol thermal emission depends on their temperature, on the PSD and the refractive index.

When retrieving aerosol properties, it is necessary either to retrieve all the above-mentioned parameters together, or to assume the knowledge of some of those parameters. In this work, we focused on the retrieval of dust aerosol vertical profiles of concentration, with the assumption that the complex refractive index, the PSD, the surface emissivity and temperature, and the atmospheric state (except aerosols) are known. This clearly leads to two challenges: the selection of appropriate data regarding both the aerosols and the surface and atmospheric state. A third challenge lies at the heart of this work: to establish the sensitivity of IASI radiances to the vertical distribution of dust and exploit it to retrieve as much information as possible.

\subsection{Aerosol's micro-physical properties}

Refractive indices of a number of substances, including desert dust aerosols, are available in databases like the Optical Properties of Aerosols and Clouds (OPAC, Hess et al., 1998), Gestion et Etudes des Informations Spectroscopiques Atmosphériques (GEISA, Jacquinet-Husson et al., 2011), the High-resolution Transmission database (HITRAN, Massie, 1994; Massie and Goldman, 2003) or the more recent Aerosols Refractive Index Archive (ARIA, http://www.atm. ox.ac.uk/project/RI/index.html). Refractive indices for desert dust found in those databases are mutually significantly different, which is most probably due to measurement uncertainties and sample composition variation. For the work presented here, we have selected the GEISA-HITRAN dust-like data set, gathered by Massie (1994); Massie and Goldman (2003) from measurements by Volz $(1972,1973)$ and Shettle and Fenn (1979) on transported Saharan dust, which seemed to allow the best reproduction of IASI measured spectra for the test-case used in this work. For sensitivity studies, we

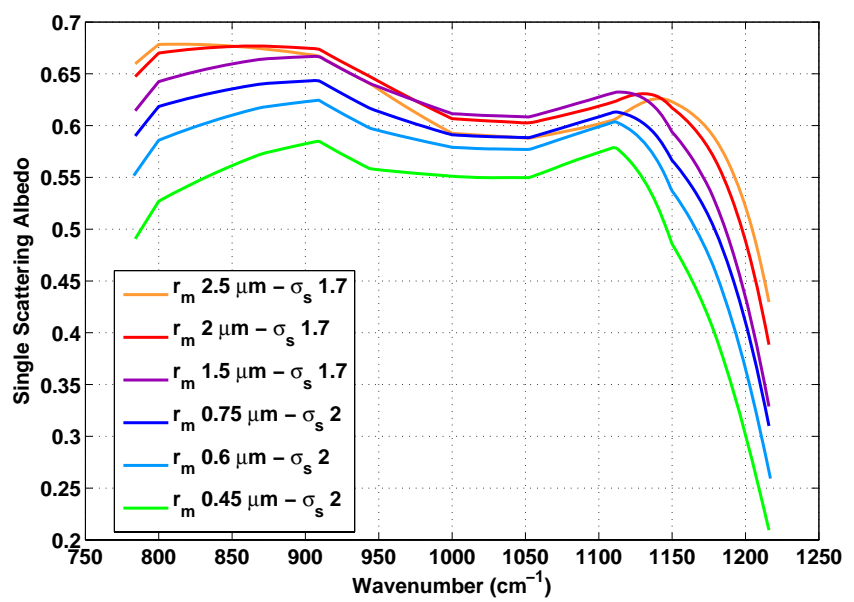

Fig. 1. Single scattering albedo computed using a Mie code, for different log-normal particle number size distributions and the dust refractive index from the GEISA-HITRAN databases.

have also used the Saharan dust refractive index set from Volz (1973), as reported in the ARIA database.

The PSD for advected dust is usually represented by lognormal distributions. There are typically two modes in dust PSDs, with median radius $\left(r_{\mathrm{m}}\right)$ of about $0.4 \mu \mathrm{m}$ and about $2 \mu \mathrm{m}$, and a geometric standard deviation $\left(\sigma_{\mathrm{s}}\right)$ of about 1.6 and 1.7, respectively (Kandler et al., 2011). These modes roughly match the mineral transported and coarse modes of OPAC dust particle number size distributions (Hess et al., 1998): $r_{\mathrm{m}}$ of 0.5 and $1.9 \mu \mathrm{m}$, respectively, $\sigma_{\mathrm{s}}$ of about 2.2 for both. The relative importance of these two modes may vary from one dust event to another, and with the distance from the source. For example, measurements at Cape Verde during the second phase of the SAMUM campain (Kandler et al., 2011) show that the ratio between the number of particles in the two dust modes is about 15 to 20 , with more particles in the smallest mode. However, it is unclear if the observed coarse mode particles are transported from the Sahara or locally produced.

We investigated the sensitivity of TIR radiances to the transported and coarse dust modes $\left(r_{\mathrm{m}}\right.$ of 0.6 and $2 \mu \mathrm{m}$, respectively, $\sigma_{\mathrm{s}}$ of 2 and 1.7, respectively), and to small radius changes. Using the SPHER Mie code designed for spherical particles (Mishchenko et al., 1999), we computed extinction cross sections and ssa's. The results are shown in Figs. 1 and 2.

The absolute values of extinction cross sections vary largely with the PSD. Therefore, to easily compare them, the extinction cross sections have been scaled in such a way that the extinction at $1000 \mathrm{~cm}^{-1}$ is the same for all PSDs. The $y$-scale on the figure is the cross section unit for the bigger particles. The scaling factors for the five other distributions are given in the figure's caption. This factor has a physical meaning: it is the ratio between the concentration necessary to reach the same OD at $1000 \mathrm{~cm}^{-1}$ using the different PSDs. 


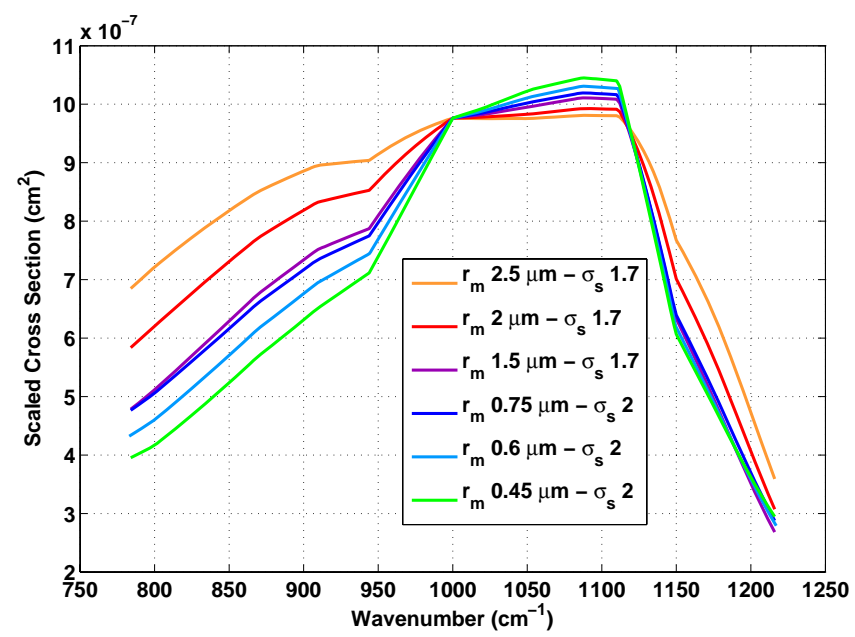

Fig. 2. Extinction cross sections computed using a Mie code, for different log-normal particle number size distributions and the dust refractive index from the GEISA-HITRAN databases. The cross sections have been scaled at $1000 \mathrm{~cm}^{-1}$, with the following multiplicative factors (from biggest to smallest particles): 1-1.7-3.513-25-64.

The comparison of the scaled cross sections reveals a different sensitivity to particle size between 800 and $950 \mathrm{~cm}^{-1}$, and above $1000 \mathrm{~cm}^{-1}$. The fact that the scaled cross sections are not much different above $1000 \mathrm{~cm}^{-1}$ does not mean that there is no sensitivity to particle size in that part of the spectrum; it means that the effect of particle size on the extinction cross sections is almost constant from 1000 to $1200 \mathrm{~cm}^{-1}$.

The ssa is about 0.6 , increasing for increasing particle sizes (except for $r_{\mathrm{m}}>1.5 \mu \mathrm{m}$ for wavenumbers between 900 and $1150 \mathrm{~cm}^{-1}$ ). Above $1125 \mathrm{~cm}^{-1}$ the scattering efficiency diminishes drastically. The maximum difference in ssa between the different size distributions used here is about 0.2 in the TIR atmospheric window.

The total impact of the PSD on the TIR radiance has been assessed by computing forward simulations (tool described in Sect. 4.1) using the surface and atmospheric conditions of a real IASI measurement $\left(17.57^{\circ} \mathrm{N}, 25.82^{\circ} \mathrm{W}, 22\right.$ June 2009 , 11:47 UTC), and both PSDs defined before. The aerosols were placed in a $1 \mathrm{~km}$-thick layer either from 1 to $2 \mathrm{~km}$ or from 4 to $5 \mathrm{~km}$ altitude, with concentration such that the $10 \mu \mathrm{m}$ OD is unity. It is clear (Fig. 3) that the size effect is mainly a change in the slopes of the V-shape, this effect being more important for aerosols at a higher altitude. The modelled brightness temperatures (BT) are almost identical around 850 to $900 \mathrm{~cm}^{-1}$ for both PSDs, and there is a maximum difference of about 1 or $2 \mathrm{~K} \mathrm{BT}$ around $1100 \mathrm{~cm}^{-1}$, for the low or high aerosol altitude, respectively. If the forward computation is undertaken in the absence of aerosols (all other parameters maintained), the BT is about 4 or $13 \mathrm{~K}$ higher, for the low or high aerosol altitude, respectively, than in the presence of dust aerosols with an OD of 1. Even though

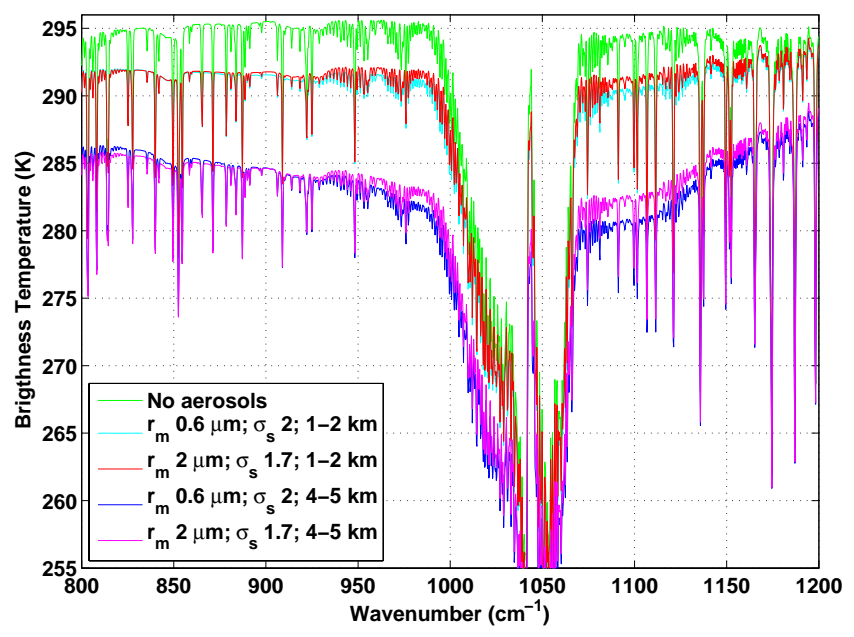

Fig. 3. Forward modelling of the radiance that would be observed by IASI for two particle size distributions associated with an aerosol layer at two different altitudes (optical depth of 1 at $10 \mu \mathrm{m}$ ). The corresponding forward modelling in absence of aerosols is also represented.

this is only one test-case, it suggests that the sensitivity to aerosol PSD, even between completely different modes, is about one degree of magnitude lower than the sensitivity to the OD. It also suggests that it would be possible to retrieve the particle size in a second step, once the vertical profile of dust concentration is known. These conclusions are coherent with those of Pierangelo et al. (2005).

For the work presented in this paper, where the main goal is to investigate the vertical distribution of desert dust in the atmosphere, we decided to use a fixed PSD, the transported mode as defined before. For sensitivity studies, we have also performed the retrievals using the dust coarse mode defined before. One should keep in mind that, when undertaking dust retrievals, a discrepancy between the residuals around 900 and $1100 \mathrm{~cm}^{-1}$ could be the sign that the particle size used for modelling dust does not match the real one.

\subsection{Atmospheric state and surface description}

For aerosol retrievals in the TIR atmospheric window, the most important ancillary data are the surface temperature and spectral emissivity, and the vertical profiles of temperature and water vapour. If data in the strong ozone absorption band (around $1040 \mathrm{~cm}^{-1}$ ) is used for the aerosol retrievals, the ozone vertical profile should also be known.

In the establishment of the retrieval strategy exposed here, we have used surface temperatures from the European Center for Medium-Range Weather Forecasts (ECMWF, stream $\mathrm{BE}$, operational surface skin temperature, linearly interpolated from the ECMWF time/space grid to the time and location of each IASI measurement), and surface emissivities from Newman et al. (2005) for the ocean and from Zhou et al. (2011) for land surfaces. The atmospheric vertical profiles of 
temperature and water vapour were taken from IASI level 2 operational products from the EUMETSAT (procession version number depends on the date of the data set, quality described in August et al., 2012). Some of these ancillary data are derived from IASI measurements, therefore it is possible that their retrieval is affected by the presence of dust in the atmosphere, as suggested by Maddy et al. (2012). However, they remain suitable for the first establishment of a dust vertical profile retrieval strategy, and the impact of plausible biases in those ancillary data on dust retrievals will be evaluated in the future.

Other relevant atmospheric gas profiles $\left(\mathrm{CO}_{2}, \mathrm{O}_{3}, \mathrm{~N}_{2} \mathrm{O}, \mathrm{CH}_{4}\right.$ and $\left.\mathrm{HNO}_{3}\right)$ are taken from the US Airforce Geophysics Laboratory tropical climatology (Anderson et al., 1986). CFC-11 $\left(\mathrm{CCl}_{3} \mathrm{~F}\right)$ and CFC-12 $\left(\mathrm{CCl}_{2} \mathrm{~F}_{2}\right)$ are also included, with atmospheric profiles from the National Center for Atmospheric Research's Whole Atmospheric Community Climate Model (WACCM, version 5, monthly mean profiles at the Izana station).

\subsection{Sensitivity to the vertical location of desert dust aerosols}

We have performed forward modelling (tool described in Sect. 4.1) in the TIR atmospheric window in the presence of a different dust load, placed in single layers at different altitudes. The net effect of dust aerosols is a reduction of radiance, meaning that the thermal emission by dust is lower than its extinction, in the considered spectral window. A higher aerosol load is required to reach the same global reduction of BT when aerosols are lower in the atmosphere. Indeed, in general the lower the aerosols, the higher their temperature and therefore the higher their thermal emission. For temperature inversion cases, where the atmospheric temperature increases from the surface upwards, it may occur that the aerosol's temperature is higher than the surface temperature. However, this would only lead to a net positive effect of aerosols on the top-of-atmosphere radiance if the aerosol's temperature is high enough with respect to the surface to counterbalance both the aerosol's absorption and scattering. Because of that, aerosol retrievals from TIR radiances are less sensitive to thermal contrasts than gas retrievals. Indeed, for gas scattering is negligible in the TIR and the only important parameter is the difference between absorption and emission, depending purely on the thermal contrast between the surface and the absorber.

A second observation from our modelling is that, for each side of the V-shape dust signature, the broadband spectral features can be reproduced within IASI radiometric noise with different dust loading/altitude pairs (see an example in Fig. 4). However, those pairs are different for the two sides of the V-shape, indicating a different sensitivity to altitude before and after the maximum aerosol extinction. The insert in Fig. 4 clearly shows that dust also affects the absorption lines of gases present in the lower troposphere (here mainly

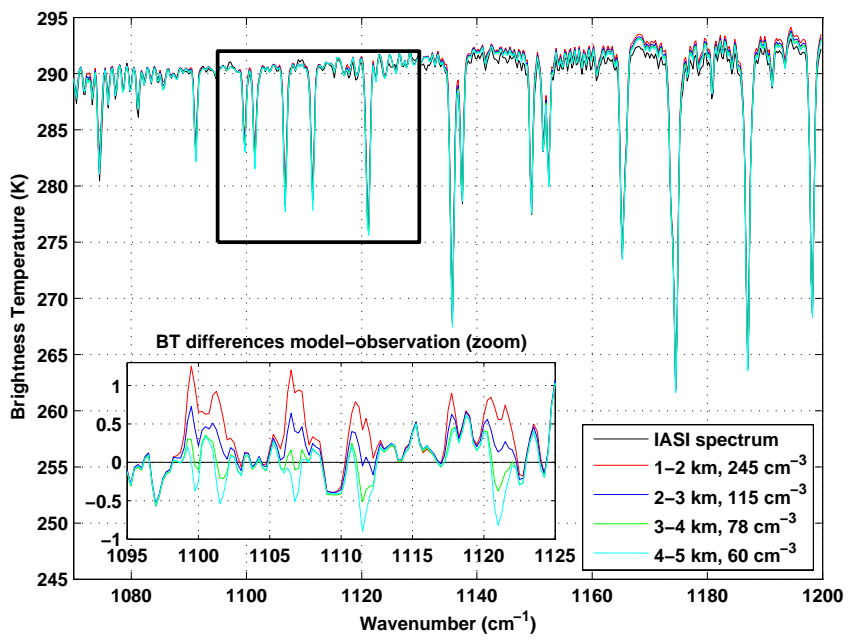

Fig. 4. Modelled brightness temperature (BT) spectra with the dust aerosol layer placed at different altitudes (aerosol concentration such that the general baseline of the spectrum is reproduced in the selected spectral window, right part of the $\mathrm{V}$-shape), and a measured IASI spectrum $\left(17.57^{\circ} \mathrm{N}, 25.82^{\circ} \mathrm{W} ; 22\right.$ June $200911: 47$ UTC). The insert shows the BT difference between the modelled spectra and the IASI spectrum, for a small wavenumbers window, emphasizing the impact on water vapour absorption lines.

water vapour) differently as a function of its altitude. The lower the aerosols in the atmosphere, the lower the gas absorption. This is explained by the high extinction due to the presence of aerosols, reducing the amount of light available for gas absorption above the aerosol layer.

It is the combination of the broadband effect of dust, the difference between both sides of the V-shape and the effect on gas absorption lines that contains the information on dust altitude. However, this sensitivity is relatively low: in the example shown, about $2 \mathrm{~K}$ BT difference for $3 \mathrm{~km}$ altitude difference (with aerosol load adapted to reproduce the broadband radiance). In comparison in this case the effect of the presence of aerosols is of about $7 \mathrm{~K}$.

Additional information on vertical sensitivity is given by derivatives of the radiance with respect to the aerosol's amount in each layer (Jacobians). Examples of Jacobians for one specific case are shown in Fig. 5 (corresponding to the first vertical profile shown in Fig. 10, where the total OD is 0.7 ). The Jacobians were plotted in a different color for the two retrieval windows defined later in Sect. 4.3, and the retrieved vertical profile of aerosols is plotted in grey (top $x$-scale). The Jacobians vary with the wavelength and in particular differ for the two retrieval windows. They show sensitivity to all altitude layers in both retrieval windows, some Jacobians being more sensitive to the lowest layers and others to the highest layers considered. Those Jacobians of course also depend on the atmospheric and surface states, but this figure shows that it is possible to have sensitivity along the whole vertical column even when the OD is non-negligible. 


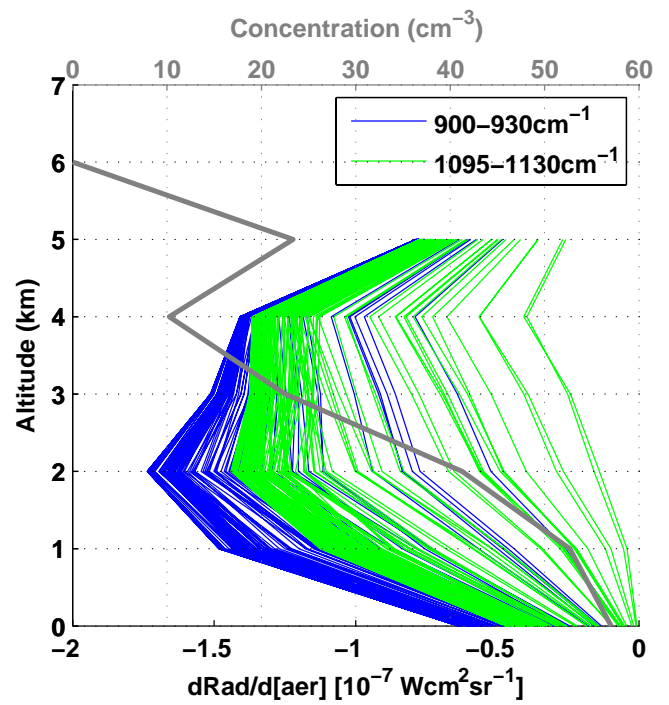

Fig. 5. Radiance derivatives with respect to aerosol amount in each layer for one specific case corresponding to the first aerosol vertical profile shown in Fig. 10. The jacobians were plotted in a different color for the two retrieval windows defined in Sect. 4.3, and the retrieved vertical profile of aerosols is plotted in grey (top $x$-scale).

To add to the complexity of dust profiles retrievals, this type of aerosol may be found at any altitude up to $6 \mathrm{~km}$ (e.g. Tsamalis et al., 2013; Winker et al., 2013), in single or multiple layers, with a high variation in the concentration. It is therefore impossible to use an a priori vertical profile with a low variance.

\section{Aerosol vertical profile retrieval strategy}

\subsection{Radiative transfer and retrieval tools}

All computations are done using the ASIMUT software package (Vandaele et al., 2008) combined with the advanced radiative transfer code LIDORT (Spurr, 2008) and the SPHER Mie code (Mishchenko et al., 1999). In this combination, SPHER is used to compute aerosol ssa, extinction cross section and expansion coefficients for Mie scattering using refractive index and PSD data; LIDORT is used for radiative transfer (including multiple scattering) and Jacobians computations; ASIMUT handles input/output, computes gas absorption parameters (line-by-line or using cross sections, and continua) and performs the retrieval part, following the Rodgers optimal estimation (OE) formalism (Rodgers, 2000). The forward modelling is computed with a $0.25 \mathrm{~cm}^{-1}$ spectral step and with a Gaussian instrument line shape $\left(0.5 \mathrm{~cm}^{-1}\right.$ full width at half maximum), as to properly reproduce the sampling and resolution of level 1c IASI data. The reflection of the radiation on the surface (assumed Lambertian) is included even though this effect is probably negligible here (low surface albedo for all types of surfaces in the TIR).

\subsection{Radiance data filtering}

IASI operational level 1c spectra are filtered prior to their use in the retrievals. Only spectra with less than $10 \%$ cloud coverage (IASI operational level 2 cloud product) are used. Spectra for which the associated water vapour profile from IASI operational level 2 data is empty or contains relative humidity values of more than $95 \%$ above $1 \mathrm{~km}$ altitude are also rejected. In order to save computation time (and prevent the OE retrieval from too many failures), aerosol retrievals are only undertaken for spectra containing a clear signature of dust aerosols. This V-shaped signature is the most visible from 1075 to $1200 \mathrm{~cm}^{-1}$ where the slope is the highest as can be seen, for example, in Fig. 3. The current test is

$\mathrm{BT}_{1085}+0.75 \mathrm{~K}<\mathrm{BT}_{1158}$

where $\mathrm{BT}_{1085}$ and $\mathrm{BT}_{1158}$ are the mean $\mathrm{BT}$ in the 1082-1087 and $1155-1160 \mathrm{~cm}^{-1}$ spectral bands, respectively.

\subsection{A two-step retrieval}

We have shown that the dust altitude sensitivity of the TIR radiance is a lot smaller than the $\mathrm{OD} /$ concentration sensitivity, and that the a priori vertical profile, required by the OE method, must be defined with a very high variance. This leads to many non-converging cases in vertical profile retrievals. To overcome that, we have designed a two-step strategy, dealing separately with the issue of radiometric noise and that of a priori. This strategy relies on the hypothesis that the atmosphere and surface are horizontally homogeneous within a $100 \mathrm{~km}$ radius circle, in their parameters impacting the long-wave radiance except for the aerosol concentration.

The first step consists in retrieving an average dust vertical profile from an average IASI TIR spectrum around the target spectrum (max $1 \mathrm{~h}$ time-difference, $100 \mathrm{~km}$ distance). This allows reducing the radiometric noise by a factor of $\sqrt{N}$ where $N$ is the number of spectra averaged. For this step, the a priori is set to 50 particles $\mathrm{cm}^{-3}$ along the whole retrieval range from 0 to $5 \mathrm{~km}$ altitude, with a $100 \%$ variance and a vertical Gaussian correlation of $1 \mathrm{~km}$ length. The result of the retrieval, a 6 points vertical profile from 0 to $5 \mathrm{~km}$ altitude, is then used as a priori with $10 \%$ variance in the second step: total column retrieval on the single target spectrum. The final vertical profile of desert dust concentration is then obtained by multiplying the vertical profile from the first step by the total column multiplicative factor from the second step. The OD is easily computed using the extinction cross sections. Here, we report the OD at $1000 \mathrm{~cm}^{-1}(10 \mu \mathrm{m})$. The full retrieval strategy is represented in Fig. 6 .

Both steps of the retrievals are performed on two spectral windows simultaneously: $900-930$ and $1095-1125 \mathrm{~cm}^{-1}$. Altitude sensitivity is present in both windows, which cover 


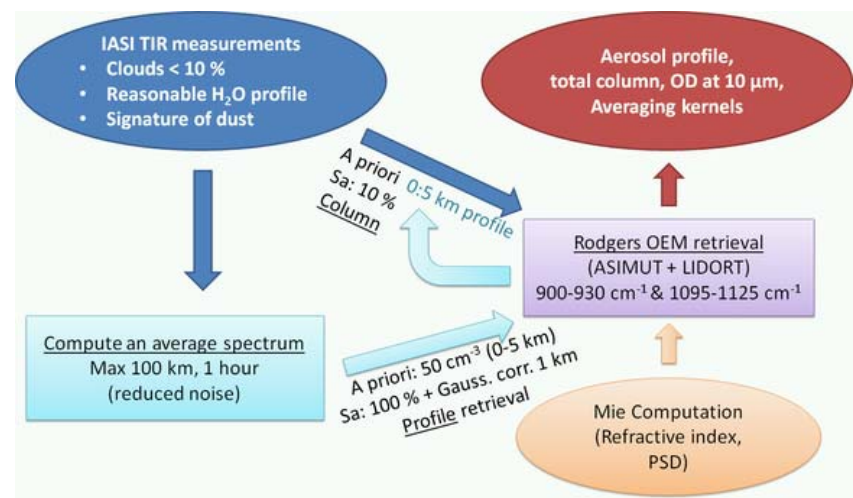

Fig. 6. Graphical representation of the retrieval strategy proposed in this work.

both sides of the V-shape, and water vapour bands sensitivity to aerosols is higher in the second retrieval window. The sensitivity to PSD is almost non-existent in the first window, and high in the second window, allowing one to detect in the retrieval residues a mismatch between the real PSD and the one used to model dust in the retrievals (only one PSD is currently used for each retrieval, but it would be possible to use a dual-mode PSD). There is currently no automatic action taken in such mismatch cases.

\section{Test-case study}

The proposed retrieval strategy was applied to a full test-case study of a large dust plume occurring both over the Atlantic Ocean and North Africa on 22 June 2009. We have treated IASI data contained in two $1300 \mathrm{~km}$ radius circles, centered at $16^{\circ} \mathrm{N}, 27^{\circ} \mathrm{W}$ and $7^{\circ} \mathrm{W}$. Data over land comprise the west part of the Saharan Desert and steppe, savanna, deciduous forest and a small part of the rain forest. The main countries covered are Western Sahara, Mauritania, Mali, southwest of Algeria, west of Niger, Senegal, Guinea, Ivory Coast, Burkina, Ghana, Togo, Benin and western part of Nigeria.

\subsection{Generalities about IASI retrieval results}

Before comparing the results with other sensors, we look at the quality of the retrievals, and their information content. First, there are IASI spectra which pass all the pre-tests described in Sect. 4.2 and for which the retrieval does not converge (represented on Figs. 7 and 8 by grey crosses). This is the case for a negligible number of ocean spectra $(<1 \%)$ but for about $15 \%$ of the land spectra, mostly in the northern part of the area studied, where the OD is probably at the limit of detection (see Fig. 9 for other sensors results). Furthermore, land retrievals are probably more inclined to fail because of additional uncertainties due to the use of surface emissivity itself obtained from IASI retrievals, lower surface emissivity (especially above deserts), higher surface temper-
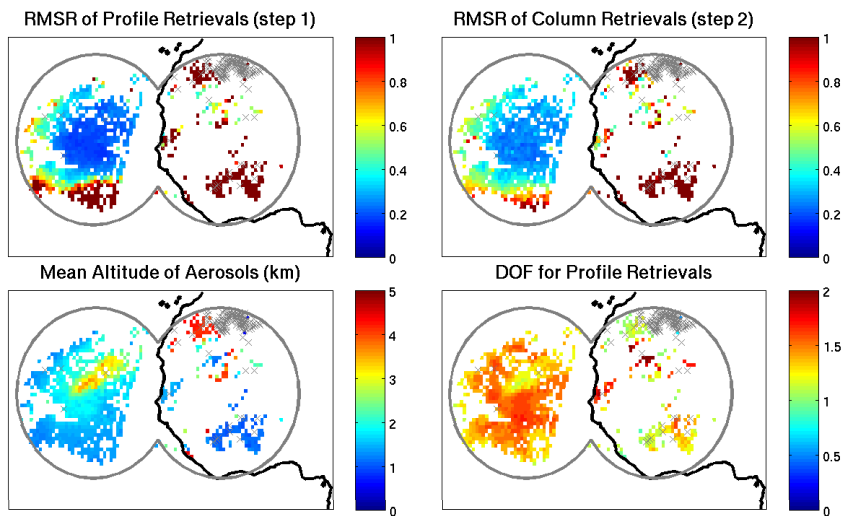

Fig. 7. Information on IASI day-time retrievals above land and offshore on 22 June 2009: root mean square of the residuals (RMSR) in BT for both steps of the retrieval, mean altitude of the aerosols and number of degrees of freedom (DOF) for the vertical profile retrieval step. Data was binned to a $0.5^{\circ} \times 0.5^{\circ}$ latitude/longitude grid. The thick grey line represents the limits of the IASI data set treated in this work. The grey crosses show unsuccessful retrievals. White space represents places where no retrieval was attempted because of the pre-filters.
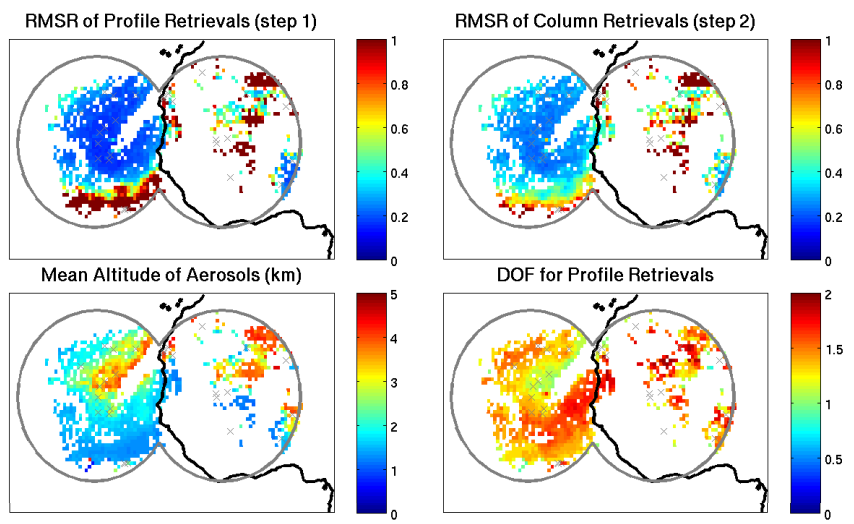

Fig. 8. Same as Fig. 7 for night-time retrievals.

atures with respect to atmospheric temperatures and lower atmospheric water vapour content. It is also probable that the assumption at the basis of the strategy (horizontal homogeneity over a $100 \mathrm{~km}$ radius circle) is less realistic over land than it is over the ocean and that the surface temperatures obtained from linear interpolation of the ECMWF data is less accurate above land because of strong not fully linear diurnal variations.

Figures 7 and 8 show information about IASI retrievals in the selected test-case: the root mean square of the residuals (RMSR) after each step of the retrieval, the mean altitude of the aerosols (altitude that cuts the total column in two halves) and the number of degrees of freedom (DOF, obtained as the trace of the averaging kernel matrix from the profile retrieval). Data was binned to a $0.5^{\circ} \times 0.5^{\circ}$ latitude/longitude 
grid. The OD and vertical profiles are shown and discussed in Sects. 5.2 and 5.3, respectively.

In general, the retrievals contain about 1.5 piece of information. For low dust loadings, the DOF is often reduced to 1.2 or even 1 . Above the desert or above the ocean during the night, the DOF may reach 2. These pieces of information do not always lie in the same portions of the vertical profile, as will be shown in Sect. 5.3, making it impossible to report each piece of information as a partial column on a standardised vertical scale.

Above the ocean, the mean altitude of the dust plume varies smoothly between 1.5 and $3 \mathrm{~km}$, which coincides with the average dust mean equivalent altitude of about $2.5 \mathrm{~km}$ reported by Peyridieu et al. (2012) for that geographic area in June. The RMSR of both steps of the retrieval is in general below $0.4 \mathrm{~K}$ (maximum about twice IASI's radiometric noise). An exception to this is at the borders of the dust plume, where the RMSR reaches $1 \mathrm{~K}$. To understand what might cause this, we looked at the residuals themselves. For retrievals with a RMSR of at least $0.5 \mathrm{~K}$, the V-shape slopes of the retrieved spectra do not match the ones from the observed spectra, with a mean residual (fitted-observed spectrum) positive in the first fitting spectral window, and negative in the second one. As already mentioned, this could be the signature of a problem in the selected aerosol particle size (here: too small particles).

Above land, the mean altitude of the dust plume is a lot more variable. Places where sharp variations of mean plume altitude are observed coincide with topographic altitude gradients (up to $300 \mathrm{~m}$ surface altitude difference along $1^{\circ}$ ). Therefore, even though we cannot fully rule out that these dust plume altitude variations could be an artefact, we believe that they are linked to the presence of different air masses. For many cases the RMSR is above $1 \mathrm{~K}$, which seems to be due to two independent reasons. First, it occurs above the desert because of slope issues as it is the case over the ocean. For all the other cases, the reason for high RMSR is a completely bad convergence, the fitted spectrum being far from the observed one. This occurs either above the desert for cases where the dust load is extremely small and placed at high altitude by our retrieval (maximum about $0.1 \mathrm{OD}$, probably actually at the limit of detection), or above nondesert land where our retrievals deliver moderate dust loadings at a very low altitude, which could be false detections. For these cases, we would recommand not to trust the result of the retrieval.

It is interesting to mention that no significant differences were observed between day- and night-time retrievals regarding their quality.

For the further interpretation of the data, we only used retrieval results with a final RMSR below $0.5 \mathrm{~K}$ above the ocean and $1 \mathrm{~K}$ above land, in order to remove data obtained with an unappropriate PSD and the land bad convergence cases.
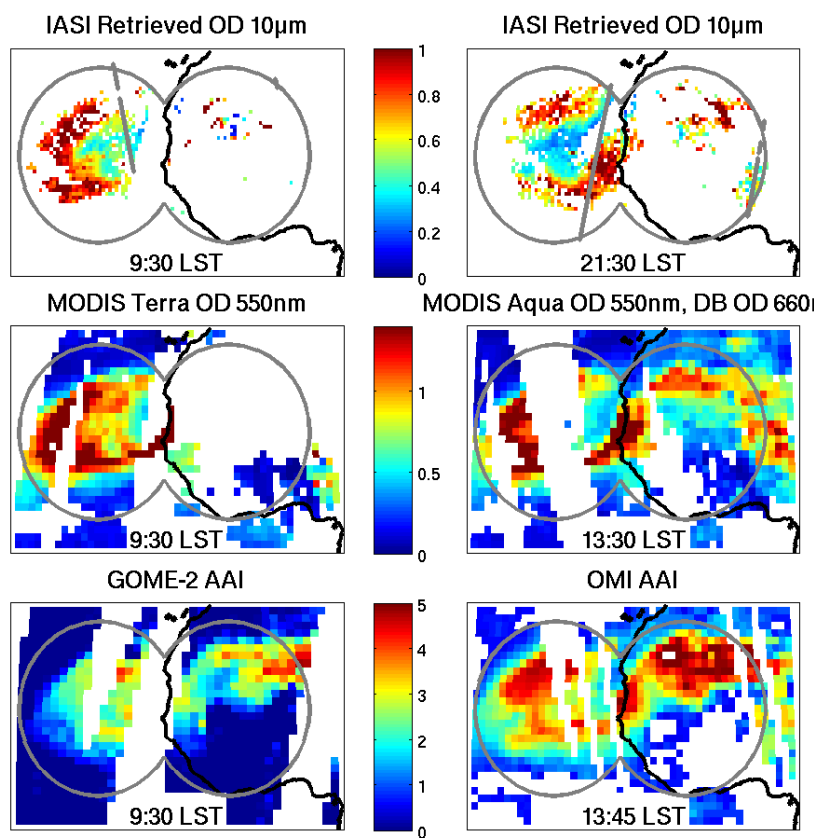

MODIS Aqua OD 550nm, DB OD 660nm
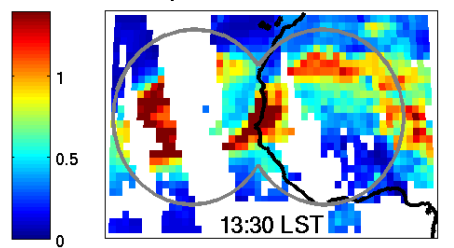

OMI AAI

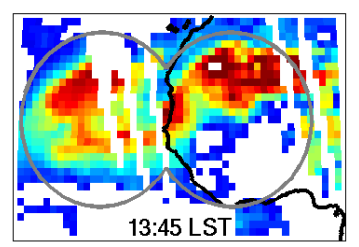

Fig. 9. Comparison, for a dust event on the 22 June 2009 above North Africa and off-shore, between the OD at $10 \mu \mathrm{m}$ retrieved from IASI TIR measurements (data was binned to a $0.5^{\circ} \times 0.5^{\circ}$ latitude/longitude grid) and aerosol data from other satellite instruments. The thick grey lines represent the limits of the IASI data set treated in this work, and CALIOP measurement co-located with a IASI spectrum (maximum $100 \mathrm{~km}, 6 \mathrm{~h}$ ). The approximate local solar time of the measurements is shown at the bottom of each map.

\subsection{Optical depth analysis and comparisons with other satellite and literature data}

Figure 9 shows OD retrievals from IASI morning and evening measurements separately (binned in a $0.5^{\circ} \times 0.5^{\circ}$ horizontal map for better comparison with the other sensors), OD from MODIS Terra and Aqua (including Deep Blue over the desert), and the AAI from GOME-2 and OMI. The approximate time for each measurement is shown on the maps. Comparisons between the different instruments show that aerosols are detected at the same places and with spatial gradients coherent between all shown instruments/algorithms. Absolute values themselves are difficult to compare for different reasons, one of them being that IASI retrievals presented here consider only dust while the comparison data contain all aerosols. A second reason is that the particle sizes observable in thermal infrared are different from those observable at UV-visible wavelengths. Considering all that, the data sets presented in Fig. 9 may be considered as matching nicely in a qualitative way.

The OD values from our retrievals are larger than the ones usually reported for TIR retrievals. Indeed, for example, Peyridieu et al. (2010) report a TIR/visible OD ratio of about 0.4 to 0.5 above the East Atlantic while in our results 
this ratio is between 0.5 and 0.7 in the same area. This is explained by the fact that here we consider the whole vertical profile of desert dust in the atmosphere, instead of a fixed single layer. Our results therefore also contain the aerosols close to the surface which have only a limited impact on the top-of-atmosphere radiance but contribute equally to the OD.

Above land, the OD from IASI retrievals is smaller when obtained from day-time measurements than from night-time ones. Even though it is not certain that this is no artefact of the method (e.g. because the result of the retrieval highly depends on the surface temperature input), this result seems reasonable with respect to the conclusions of Kocha et al. (2013). Indeed, the higher OD we observe during the night above the desert occurs in the regions highlighted in Kocha et al. (2013) as sources with maximum emission in the evening (Adrar des Ifoghas and Hoggar Mountains regions and the Airr foothills). Furthermore our retrievals always place aerosols in the lower layers (either aerosols are continuously present from 0 to $6 \mathrm{~km}$ altitude, or two layers are identified, one below $2 \mathrm{~km}$ altitude and one mainly above $3 \mathrm{~km}$ altitude), which is coherent with the superimposition of transported and locally produced dust.

For the night-time IASI retrievals, where the coverage includes the coastal area, the OD varies smoothly across the coast. This can be seen as an indication that our strategy is in general as reliable over land as it is over ocean, provided that the bad convergence cases are filtered out.

All those results and comparisons mainly show that our retrievals produce reasonable results in terms of total OD and quality of fit, under all conditions even though a smaller amount of reliable results could be obtained above land than above the ocean.

\subsection{Vertical profiles comparisons with CALIOP}

In this section, we compare the IASI-retrieved profiles with extinction retrievals from CALIOP. CALIOP measurements co-located with IASI spectra (maximum $100 \mathrm{~km}$ and $6 \mathrm{~h}$ difference) are shown as grey dots forming a thick line along CALIPSO's track in Fig. 9. For the event under study in the geographic area considered, it is clear that during the day CALIOP measurements only occurred above the ocean where the IASI retrieved OD is moderate (maximum about 0.5). During the night, CALIOP measurements over the ocean cross high aerosol load areas. Over land, most coincidences occur in areas with IASI retrieved OD below 0.5 , over Nigeria and Niger, in areas identified as sources in Kocha et al. (2013).

Typical comparisons between our retrieved aerosol concentration profiles and CALIOP extinction vertical profiles are shown in Fig. 10. For all the comparisons shown, the number of coincident CALIOP measurements was higher than 30. CALIOP mean coincident data is plotted in a different color for the different aerosol subtypes: orange for dust, grey for unidentified, blue for marine aerosols (follow- ing Winker et al., 2013, dust in the marine boundary layer is often classified in the CALIOP product as marine aerosol or polluted dust). IASI retrievals are shown in green on a distinct $x$-scale placed at the top of the figure. The averaging kernels from the first step of the retrievals are also shown in dashed green lines, the $x$-scale (not visible) being 0 to 1 . An insert shows the IASI retrieved OD map after RMSR filtering (same color scale as in Fig. 9) with a black star marking the location of the represented vertical profile.

Our retrievals seem to allow catching dust aerosols at all altitudes even right above the surface, in single or double layers, and do catch aerosols classified in CALIOP data as dust, polluted dust (not shown), or unidentified. The sensitivity to altitude, in the form of averaging kernels (from the first step of the retrievals), varies a lot. Sometimes there is sensitivity all along the retrieval altitude range, but sometimes only to a subset of altitudes, which may be either a large layer in the higher or lower part of the retrieval altitudes, or two distinct layers. Those averaging kernels are therefore important to report together with the retrieved profiles to allow proper use of the data.

After carefully reviewing all the IASI-CALIOP comparisons in our test-case, of which only a few examples may be shown here, there seems to be only one parameter that governs the extent of agreement between the two instruments: the aerosol load. Under low dust load, our retrievals place the main aerosol layer 1 to $2 \mathrm{~km}$ higher than CALIOP extinction retrievals. Under moderate to high dust load, our retrievals mainly reproduce CALIOP retrievals, being over the ocean, over the desert or over semi-arid areas. This dependence of the quality of the retrieved vertical profiles with the aerosol load would be perfectly reasonable because the altitude sensitivity in TIR is lower than the total column sensitivity, making it more difficult to retrieve the vertical profile for a low aerosol loading. However, the observed differences between our profiles and the extinction data from CALIOP may be partly due to other reasons than our retrievals themselves, like temporal evolution of the plume during the $4 \mathrm{~h}$ between measurements by both instruments, uncertainties in CALIOP retrievals, or a different ratio between small and large particles between the low and high aerosols load areas (with a different impact on $1.064 \mu \mathrm{m}$ extinction than on TIR OD).

\subsection{Sensitivity of the retrievals to the aerosol's microphysical properties}

Until now, we had fixed the aerosol's PSD and refractive index to a plausible arbitrarily selected set of data. As there are many other possibilities for this selection, it is quite important to be aware of the impact of such a choice on the retrieval results.

Our first test concerns the refractive index data set. We have performed all retrievals from our test-case using the refractive index from Volz (1973), which is, among all refractive indices for Saharan dust, one of the most different 

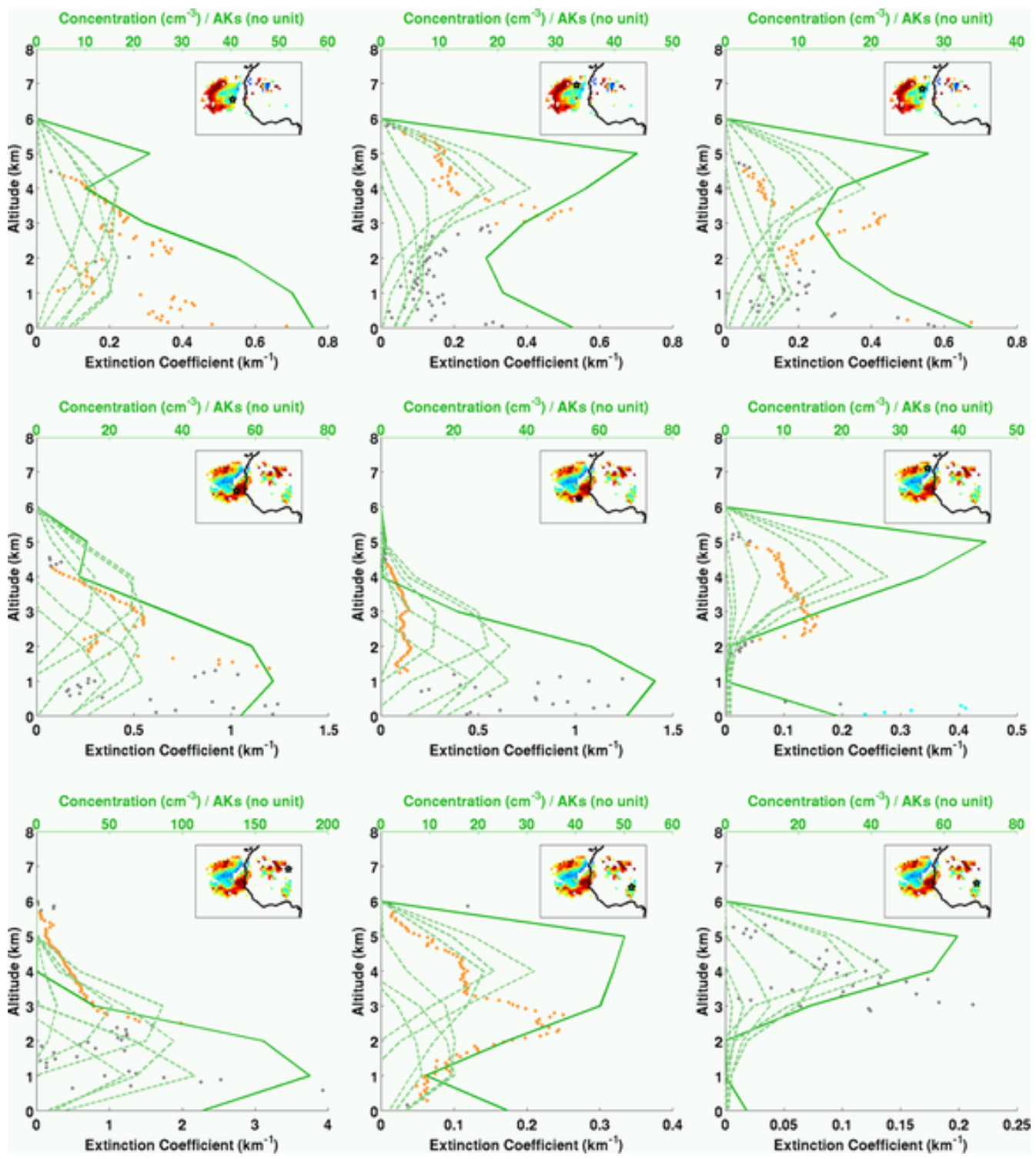

Fig. 10. Example of comparisons between IASI vertical profiles of concentration (green) and CALIOP extinction profiles (average of all measurements within $100 \mathrm{~km}$ and $6 \mathrm{~h}$ from the IASI measurement, shown as dots with color depending on the aerosol type reported in CALIOP data). The green dashed lines represent the averaging kernels from the first step of the retrieval (scale not shown, from 0 to 1 ). On each figure, an insert shows the corresponding OD map, with the location of the specific vertical profile shown as a black star.

data set with respect to the GEISA-HITRAN data set used for the rest of this work. The results of these retrievals are globally close to the ones shown in Fig. 9. The plume is reproduced with both refractive indices, but OD results with the Volz refractive index are more scattered and oneto-one OD comparisons show up to $\pm 30 \%$ difference with GEISA-HITRAN-based retrievals. The RMSR is in general higher when using Volz refractive index, especially above land where almost no retrieval converges with a RMSR below $1 \mathrm{~K}$. Furthermore, there are more cases of unsuccessful retrievals when using Volz refractive indices $(8 \%$ over the ocean instead of less than $1 \%$, and $30 \%$ over land instead of $15 \%)$. The mean altitude of the retrieval is globally the same for both cases, again a little bit noisier for Volz-based retrievals. Vertical profile comparisons show only small differences, but GEISA-HITRAN-based retrievals place more aerosols in the lower layers (below $2 \mathrm{~km}$ ) than Volz-based retrievals. Finally, the DOF is on average 0.2 (ocean) or 0.3 (land) higher for Volz-based retrievals.

The second test consisted in using the dust coarse mode PSD. All retrievals were performed using that PSD. The a priori concentration was divided by 100 to take into account the extinction cross sections difference. The number of unsuccessful retrievals was about the same as with the 
transported mode. Over land, it is very difficult to conclude as to which PSD provides the best results, and maybe the reality is a combination of both. Results for the coarse mode over the ocean show a globally lower OD (up to $50 \%$ difference), with a higher RMSR except at the borders of the plume, where we have mentioned in Sect. 5.2 that the residuals presented the signature of a possibly too small particle size. For those specific cases, the RMSR and residuals are a lot better for coarse mode than for transported mode retrievals. Retrievals with the coarse mode PSD place aerosols on average about $1 \mathrm{~km}$ higher than when using the transported mode (which explains partly the high OD difference), with a DOF of 1 to 1.2 , thus about 0.5 lower than when using the transported mode. The vertical profiles are almost always a single wide layer, with very little sensitivity to the surface. Those profiles compare worse with CALIOP extinction data. However, there are no comparisons for cases where the transported PSD gave retrievals with a high RMSR (where indeed the PSD is probably closer to the coarse mode than to the transported mode).

As conclusions to these sensitivity studies, it seems that the choice of refractive index is not too critical for the obtention of a reasonable data set of vertical profiles of desert dust, but has a non-negligible impact on the number of successful (and with reasonable RMSR) retrievals, especially above land. The choice of PSD is on the other hand very important to obtain reliable ODs and vertical profiles. However, a careful examination of the RMSR spectral dependence is a hint to detect a badly defined PSD. In the future, we plan to investigate the possibility to retrieve the PSD and/or refractive index using the linearised Mie code from Spurr et al. (2012) combined with LIDORT.

\section{Conclusion and further work}

Desert dust is a prominent tropospheric aerosol, with nonnegligible climatic impact containing both a natural and an anthropogenic part. The radiative effect of this aerosol depends on many parameters, among which the vertical distribution is currently poorly characterized. In this work, we have designed a strategy to retrieve desert dust concentration vertical profiles from thermal infrared (TIR) radiance measurements by the IASI instrument onboard the Metop satellite series. We have shown that the altitude sensitivity lies in both the broadband extinction by dust, which occurs with a typical V-shape in the TIR atmospheric window, and in the effect dust has on absorption by tropospheric gases (as water vapour). However the sensitivity of TIR radiances to dust altitude is about one order of magnitude lower than the sensitivity to the optical depth (OD).

Our retrievals are based on the Optimal Estimation formalism (Rodgers, 2000), and use the advanced radiative transfer code LIDORT (Spurr, 2008). The strategy contains two steps, to deal separately with the problems of low sensitivity to altitude and of difficult a priori definition. The first step consists in a vertical profile retrieval from an average of $N$ IASI spectra contained in a $100 \mathrm{~km}$-radius circle, with radiometric noise reduced by a factor $\sqrt{N}$. The a priori is a constant value along $0-5 \mathrm{~km}$ altitude, with $100 \%$ variance and a Gaussian $1 \mathrm{~km}$ vertical correlation. The second step is a total column retrieval from a single IASI spectrum, using as a priori the vertical profile obtained in the previous step and $10 \%$ variance. We use two spectral windows, on both sides of the V-shape dust spectral signature, with different sensitivity to dust altitude and to particle size.

Application of this strategy to a test-case dust event and comparison with other satellite data for the same event and with dust source locations, have shown that our retrievals provide very reasonable results in terms of both vertical profiles and OD, above all surfaces considered, during day and night. The vertical profiles contain in general 1.5 pieces of information, and the averaging kernels show sensitivity to different portions of the low troposphere depending on the surface and atmospheric conditions. A sensitivity study has shown that the choice of refractive index (within realistic data sets) is not critical for the vertical profiles retrievals, but that selecting an unappropriate particle size distribution may have dramatic consequences on both the retrieved vertical profile and the total OD.

The retrieval strategy presented in this work offers a unique way to gather information on the 3-D distribution of desert dust in the atmosphere, allowing to measure its vertical profile over not only the ocean but also land areas, with full coverage twice daily. It furthermore provides unique insight in day-night differences, especially close to source areas.

While we have demonstrated here the concept and some applications, it is obvious that more investigations need to be undertaken in relation with those profile retrievals. First, because the altitude sensitivity is partly found in the effect dust has on water vapour absorption bands, and because all thermal emission terms are crucial for our retrievals, we will in the future investigate the sensitivity of the retrievals to uncertainties in surface temperature and emissivity, and in atmospheric vertical profiles of temperature and water vapour. Second, we plan to investigate ways for reducing the computational time needed, for example, changes in the strategy with respect to the a priori definition. Third, we will investigate how combining IASI/Metop-A and B platforms could improve our retrievals. Finally, we also plan to investigate the possibility for retrieval of the particle size and/or refractive index using the linerarised Mie code from Spurr et al. (2012).

Acknowledgements. This work could not have been done without satellite data sets. We therefore greatly acknowledge the EUMETSAT and EUMETCast service for IASI data, the NASA Atmospheric Science Data Center and the CNES for CALIOP data, the NASA Level 1 and Atmosphere Archive and Distribution System (LAADS) for MODIS data, the Tropospheric Emission 
Monitoring Internet Service (TEMIS) for OMI and GOME-2 AAI data. S. V. acknowledges the Belgian Science Policy/ESA A3C PRODEX program, the Belgian Science Policy "supplementary researcher" program and personal BIRA-IASB resources for funding. A. C. V. acknowledges the support of the "Interuniversity Attraction Poles" programme financed by the Belgian government (Planet TOPERS). S. V. is thankful to the following persons for useful discussions: V. Capelle, L. Clarisse, N. Clerbaux, S. Dewitte, L. Klüser, S. Nevens, R. Spurr, C. Tsamalis, and the IT service at BIRA-IASB.

Edited by: A. Kokhanovsky

\section{References}

Anderson, G. P., Clough, S. A., Kneizys, F., Chetwynd, J. H., and Shettle, E. P.: AFGL atmospheric constituent profiles (0$120 \mathrm{~km}$ ), Environmental research papers, Hanscom AFB, Mass., no. 954, 1986.

Ansmann, A., Petzold, A., Kandler, K., Tegen, I., Wendisch, M., Müller, D., Weinzierl, B., Müller, T., and Heintzenberg, J.: Saharan Mineral Dust Experiments SAMUM-1 and SAMUM-2: what have we learned?, Tellus B, 63, 403-429, doi:10.1111/j.1600-0889.2011.00555.x, 2011.

August, T., Klaes, D., Schlüssel, P., Hultberg, T., Crapeau, M., Arriaga, A., O'Carroll, A., Coppens, D., Munro, R., and Calbet, X.: IASI on Metop-A: operational level 2 retrievals after five years in orbit, J. Quant. Spectrosc. Ra., 113, 1340-1371, doi:10.1016/j.jqsrt.2012.02.028, 2012.

Bangert, M., Nenes, A., Vogel, B., Vogel, H., Barahona, D., Karydis, V. A., Kumar, P., Kottmeier, C., and Blahak, U.: Saharan dust event impacts on cloud formation and radiation over Western Europe, Atmos. Chem. Phys., 12, 4045-4063, doi:10.5194/acp-124045-2012, 2012.

Carboni, E., Thomas, G. E., Sayer, A. M., Siddans, R., Poulsen, C. A., Grainger, R. G., Ahn, C., Antoine, D., Bevan, S., Braak, R., Brindley, H., DeSouza-Machado, S., Deuzé, J. L., Diner, D., Ducos, F., Grey, W., Hsu, C., Kalashnikova, O. V., Kahn, R., North, P. R. J., Salustro, C., Smith, A., Tanré, D., Torres, O., and Veihelmann, B.: Intercomparison of desert dust optical depth from satellite measurements, Atmos. Meas. Tech., 5, 1973-2002, doi:10.5194/amt-5-1973-2012, 2012.

Christopher, S. A., Johnson, B., Jones, T. A., and Haywood, J.: Vertical and spatial distribution of dust from aircraft and satellite measurements during the GERBILS field campaign, Geophys. Res. Lett., 36, L06806, doi:10.1029/2008GL037033, 2009.

Claquin, T., Schulz, M., Balkanski, Y., and Boucher, O.: Uncertainties in assessing radiative forcing by mineral dust, Tellus B, 50, 491-505, doi:10.1034/j.1600-0889.1998.t01-2-00007.x, 1998.

Clerbaux, C., Boynard, A., Clarisse, L., George, M., HadjiLazaro, J., Herbin, H., Hurtmans, D., Pommier, M., Razavi, A., Turquety, S., Wespes, C., and Coheur, P.-F.: Monitoring of atmospheric composition using the thermal infrared IASI/MetOp sounder, Atmos. Chem. Phys., 9, 6041-6054, doi:10.5194/acp9-6041-2009, 2009. de Graaf, M., Stammes, P., Torres, O., and Koelemeijer, R. B. A.: Absorbing Aerosol Index: Sensitivity analysis, application to GOME and comparison with TOMS, J. Geophys. Res., 110, D01201, doi:10.1029/2004JD005178, 2005.

De Paepe, B. and Dewitte, S.: Dust aerosol optical depth retrieval over a desert surface using the SEVIRI window channels, J. Atmos. Ocean. Tech., 26, 704-718, doi:10.1175/2008JTECHA1109.1, 2009.

DeSouza-Machado, S. G., Strow, L. L., Imbiriba, B., McCann, K., Hoff, R. M., Hannon, S. E., Martins, J. V., Tanré, D., Deuzé, J. L., Ducos, F., and Torres, O.: Infrared retrievals of dust using AIRS: comparisons of optical depths and heights derived for a North African dust storm to other collocated EOS A-Train and surface observations, J. Geophys. Res., 115, D15201, doi:10.1029/2009JD012842, 2010.

Forster, P., Ramaswamy, V., Artaxo, P., Berntsen, T., Betts, R., Fahey, D., Haywood, J., Lean, J., Lowe, D., Myhre, G., Nganga, J., Prinn, R., Raga, G., Schulz, M., and Dorland, R. V.: Changes in atmospheric constituents and in radiative forcing, in: Climate Change 2007: The Physical Science Basis. Contribution of Working Group I to the Fourth Assessment Report of the Intergovernmental Panel on Climate Change, Cambridge University Press, Cambridge, UK and New York, NY, USA, 167-168, 2007.

Hess, M., Koepke, P., and Schult, I.: Optical properties of aerosols and clouds: the software package OPAC, B. Am. Meteorol. Soc., 79, 831-844, doi:10.1175/15200477(1998)079<0831:OPOAAC>2.0.CO;2, 1998.

Jacquinet-Husson, N., Crepeau, L., Armante, R., Boutammine, C., Chédin, A., Scott, N., Crevoisier, C., Capelle, V., Boone, C., Poulet-Crovisier, N., Barbe, A., Campargue, A., Chris Benner, D., Benilan, Y., Bézard, B., Boudon, V., Brown, L., Coudert, L., Coustenis, A., Dana, V., Devi, V., Fally, S., Fayt, A., Flaud, J.-M., Goldman, A., Herman, M., Harris, G., Jacquemart, D., Jolly, A., Kleiner, I., Kleinböhl, A., KwabiaTchana, F., Lavrentieva, N., Lacome, N., Xu, L.-H., Lyulin, O., Mandin, J.-Y., Maki, A., Mikhailenko, S., Miller, C., Mishina, T., Moazzen-Ahmadi, N., Müller, H., Nikitin, A., Orphal, J., Perevalov, V., Perrin, A., Petkie, D., Predoi-Cross, A., Rinsland, C., Remedios, J., Rotger, M., Smith, M., Sung, K., Tashkun, S., Tennyson, J., Toth, R., Vandaele, A.-C., and Vander Auwera, J.: The 2009 edition of the GEISA spectroscopic database, J. Quant. Spectrosc. Ra., 112, 2395-2445, doi:10.1016/j.jqsrt.2011.06.004, 2011.

Kandler, K., Sschütz, L., Jäckel, S., Lieke, K., Emmel, C., Müller-Ebert, D., Ebert, M., Scheuvens, D., Schladitz, A., Åegvić, B., Wiedensohler, A., and Weinbruch, S.: Ground-based off-line aerosol measurements at Praia, Cape Verde, during the Saharan Mineral Dust Experiment: microphysical properties and mineralogy, Tellus B, 63, 459-474, doi:10.1111/j.16000889.2011.00546.x, 2011.

Klüser, L., Martynenko, D., and Holzer-Popp, T.: Thermal infrared remote sensing of mineral dust over land and ocean: a spectral SVD based retrieval approach for IASI, Atmos. Meas. Tech., 4, 757-773, doi:10.5194/amt-4-757-2011, 2011.

Klüser, L., Kleiber, P., Holzer-Popp, T., and Grassian, V.: Desert dust observation from space - application of measured mineral component infrared extinction spectra, Atmos. Environ., 54, 419-427, doi:10.1016/j.atmosenv.2012.02.011, 2012. 
Kocha, C., Tulet, P., Lafore, J.-P., and Flamant, C.: The importance of the diurnal cycle of Aerosol Optical Depth in West Africa, Geophys. Res. Lett., 40, 785-790, doi:10.1002/grl.50143, 2013.

Koehler, K. A., Kreidenweis, S. M., DeMott, P. J., Petters, M. D., Prenni, A. J., and Möhler, O.: Laboratory investigations of the impact of mineral dust aerosol on cold cloud formation, Atmos. Chem. Phys., 10, 11955-11968, doi:10.5194/acp-1011955-2010, 2010.

Lee, S.-S.: Atmospheric science: aerosols, clouds and climate, Nat. Geosci., 4, 826-827, doi:10.1038/ngeo1340, 2011.

Li, Z., Niu, F., Fan, J., Liu, Y., Rosenfeld, D., and Ding, Y.: Long-term impacts of aerosols on the vertical development of clouds and precipitation, Nat. Geosci., 4, 888-894, doi:10.1038/ngeo1313, 2011.

Liao, H. and Seinfeld, J. H.: Radiative forcing by mineral dust aerosols: sensitivity to key variables, J. Geophys. Res., 103, 31637-31645, doi:10.1029/1998JD200036, 1998.

Maddy, E. S., DeSouza-Machado, S. G., Nalli, N. R., Barnet, C. D., L Strow, L., Wolf, W. W., Xie, H., Gambacorta, A., King, T. S., Joseph, E., Morris, V., Hannon, S. E., and Schou, P.: On the effect of dust aerosols on AIRS and IASI operational level 2 products, Geophys. Res. Lett., 39, L10809, doi:10.1029/2012GL052070, 2012.

Massie, S.: Indices of refraction for the Hitran compilation, J. Quant. Spectrosc. Ra., 52, 501-513, doi:10.1016/00224073(94)90176-7, 1994.

Massie, S. and Goldman, A.: The infrared absorption cross-section and refractive-index data in HITRAN, J. Quant. Spectrosc. Ra., 82, 413-428, doi:10.1016/S0022-4073(03)00167-5, 2003.

Mishchenko, M. I., Dlugach, J. M., Yanovitskij, E. G., and Zakharova, N. T.: Bidirectional reflectance of flat, optically thick particulate layers: an efficient radiative transfer solution and applications to snow and soil surfaces, J. Quant. Spectrosc. Ra., 63, 409-432, doi:10.1016/S0022-4073(99)00028-X, 1999.

Newman, S. M., Smith, J. A., Glew, M. D., Rogers, S. M., and Taylor, J. P.: Temperature and salinity dependence of sea surface emissivity in the thermal infrared, Q. J. Roy. Meteor. Soc., 131, 2539-2557, doi:10.1256/qj.04.150, 2005.

Perrone, M. R., Tafuro, A., and Kinne, S.: Dust layer effects on the atmospheric radiative budget and heating rate profiles, Atmos. Environ., 59, 344-354, doi:10.1016/j.atmosenv.2012.06.012, 2012.

Peyridieu, S., Chédin, A., Tanré, D., Capelle, V., Pierangelo, C., Lamquin, N., and Armante, R.: Saharan dust infrared optical depth and altitude retrieved from AIRS: a focus over North Atlantic - comparison to MODIS and CALIPSO, Atmos. Chem. Phys., 10, 1953-1967, doi:10.5194/acp-10-1953-2010, 2010.

Peyridieu, S., Chédin, A., Capelle, V., Tsamalis, C., Pierangelo, C., Armante, R., Crevoisier, C., Crépeau, L., Siméon, M., Ducos, F., and Scott, N. A.: Characterization of dust aerosols in the infrared from IASI and comparison with PARASOL, MODIS, MISR, CALIOP, and AERONET observations, Atmos. Chem. Phys. Discuss., 12, 23093-23133, doi:10.5194/acpd-12-230932012, 2012.

Pierangelo, C., Chédin, A., Heilliette, S., Jacquinet-Husson, N., and Armante, R.: Dust altitude and infrared optical depth from AIRS, Atmos. Chem. Phys., 4, 1813-1822, doi:10.5194/acp-41813-2004, 2004.
Pierangelo, C., Mishchenko, M., Balkanski, Y., and Chédin, A.: Retrieving the effective radius of Saharan dust coarse mode from AIRS, Geophys. Res. Lett., 32, L20813, doi:10.1029/2005GL023425, 2005.

Quijano, A. L., Sokolik, I. N., and Toon, O. B.: Radiative heating rates and direct radiative forcing by mineral dust in cloudy atmospheric conditions, J. Geophys. Res., 105, 12207-12219, doi:10.1029/2000JD900047, 2000.

Redemann, J., Vaughan, M. A., Zhang, Q., Shinozuka, Y., Russell, P. B., Livingston, J. M., Kacenelenbogen, M., and Remer, L. A.: The comparison of MODIS-Aqua (C5) and CALIOP (V2 \& V3) aerosol optical depth, Atmos. Chem. Phys., 12, 30253043, doi:10.5194/acp-12-3025-2012, 2012.

Remer, L. A., Tanré, D., Kaufman, Y. J., Ichoku, C., Mattoo, S., Levy, R., Chu, D. A., Holben, B., Dubovik, O., Smirnov, A., Martins, J. V., Li, R.-R., and Ahmad, Z.: Validation of MODIS aerosol retrieval over ocean, Geophys. Res. Lett., 29, 8008, doi:10.1029/2001GL013204, 2002.

Rodgers, C. D.: Inverse methods for atmospheric sounding - theory and practice, in: Series on Atmospheric, Oceanic and Planetary Physics, Vol. 2, World Scientific, 65-100, 2000.

Shettle, E. P. and Fenn, R. W.: Models for the Aerosols of the Lower Atmosphere and the Effects of Humidity Variations on Their Optical Properties, AFGL-TR-79-0214, 1979.

Sokolik, I. N.: The spectral radiative signature of windblown mineral dust: implications for remote sensing in the thermal IR region, Geophys. Res. Lett., 29, 2154, doi:10.1029/2002GL015910, 2002.

Sokolik, I. N., Toon, O. B., and Bergstrom, R. W.: Modeling the radiative characteristics of airborne mineral aerosols at infrared wavelengths, J. Geophys. Res., 103, 8813-8826, doi:10.1029/98JD00049, 1998.

Spurr, R.: LIDORT and VLIDORT: linearized pseudo-spherical scalar and vector discrete ordinate radiative transfer models for use in remote sensing retrieval problems, in: Light Scattering Reviews 3, edited by: Kokhanovsky, A. A., Springer Praxis Books, Springer Berlin Heidelberg, 229-275, doi:10.1007/978-3-54048546-9_7, 2008.

Spurr, R., Wang, J., Zeng, J., and Mishchenko, M. I.: Linearized T-matrix and Mie scattering computations, J. Quant. Spectrosc. Ra., 113, 425-439, doi:10.1016/j.jqsrt.2011.11.014, 2012.

Textor, C., Schulz, M., Guibert, S., Kinne, S., Balkanski, Y., Bauer, S., Berntsen, T., Berglen, T., Boucher, O., Chin, M., Dentener, F., Diehl, T., Easter, R., Feichter, H., Fillmore, D., Ghan, S., Ginoux, P., Gong, S., Grini, A., Hendricks, J., Horowitz, L., Huang, P., Isaksen, I., Iversen, I., Kloster, S., Koch, D., Kirkevåg, A., Kristjansson, J. E., Krol, M., Lauer, A., Lamarque, J. F., Liu, X., Montanaro, V., Myhre, G., Penner, J., Pitari, G., Reddy, S., Seland, Ø., Stier, P., Takemura, T., and Tie, X.: Analysis and quantification of the diversities of aerosol life cycles within AeroCom, Atmos. Chem. Phys., 6, 1777-1813, doi:10.5194/acp-6-1777-2006, 2006.

Tsamalis, C., Chédin, A., Pelon, J., and Capelle, V.: The seasonal vertical distribution of the Saharan Air Layer and its modulation by the wind, Atmos. Chem. Phys. Discuss., 13, 4727-4784, doi:10.5194/acpd-13-4727-2013, 2013. 
Vandaele, A. C., De Mazière, M., Drummond, R., Mahieux, A., Neefs, E., Wilquet, V., Korablev, O., Fedorova, A., Belyaev, D., Montmessin, F., and Bertaux, J.-L.: Composition of the Venus mesosphere measured by Solar Occultation at Infrared on board Venus Express, J. Geophys. Res., 113, E00B23, doi:10.1029/2008JE003140, 2008.

Volz, F.: Infrared refractive index of atmospheric aerosol substances, Appl. Optics, 11, 755-759, 1972.

Volz, F. E.: Infrared optical constants of ammonium sulfate, Sahara dust, volcanic pumice, and flyash, Appl. Optics, 12, 564-568, doi:10.1364/AO.12.000564, 1973.

Winker, D. M., Vaughan, M. A., Omar, A., Hu, Y., Powell, K. A., Liu, Z., Hunt, W. H., and Young, S. A.: Overview of the CALIPSO mission and CALIOP data processing algorithms, J. Atmos. Ocean. Technol., 26, 2310-2323, doi:10.1175/2009JTECHA1281.1, 2009.

Winker, D. M., Tackett, J. L., Getzewich, B. J., Liu, Z., Vaughan, M. A., and Rogers, R. R.: The global 3-D distribution of tropospheric aerosols as characterized by CALIOP, Atmos. Chem. Phys., 13, 3345-3361, doi:10.5194/acp-13-33452013, 2013
Zhang, J. and Christopher, S. A.: Longwave radiative forcing of Saharan dust aerosols estimated from MODIS, MISR, and CERES observations on Terra, Geophys. Res. Lett., 30, 2188, doi:10.1029/2003GL018479, 2003.

Zhang, L., Li, Q. B., Gu, Y., Liou, K. N., and Meland, B.: Improved estimate of global dust radiative forcing using a coupled chemical transport-radiative transfer model, Atmos. Chem. Phys. Discuss., 13, 2415-2456, doi:10.5194/acpd-13-2415-2013, 2013.

Zhang, P., Lu, N.-M., Hu, X.-Q., and Dong, C.-H.: Identification and physical retrieval of dust storm using three MODIS thermal IR channels, Global Planet. Change, 52, 197-206, doi:10.1016/j.gloplacha.2006.02.014, 2006.

Zhou, D., Larar, A., Liu, X., Smith, W., Strow, L., Yang, P., Schlüssel, P., and Calbet, X.: Global land surface emissivity retrieved from satellite ultraspectral IR measurements, IEEE T. Geosci. Remote, 49, 1277-1290, doi:10.1109/TGRS.2010.2051036, 2011. 